\title{
Avaliação da influência de agregados leves de argila calcinada no desempenho de concretos estruturais
}

\author{
Evaluation of the influence of calcined clay lightweight \\ aggregates on the performance of structural concretes
}

\section{Bruno Carlos de Santis João Adriano Rossignolo}

\section{Resumo \\ $\mathbf{E}$} ste trabalho tem por objetivo a avaliação de desempenho de concretos leves produzidos com agregados leves de argila calcinada.

Primeiramente, foram coletadas e caracterizadas diferentes amostras de solo (argila) do estado de São Paulo. Em seguida, foram confeccionados corpos de prova de argila calcinada com as diferentes massas cerâmicas coletadas. Os corpos de prova confeccionados com essas massas cerâmicas, queimados à temperatura de $900^{\circ} \mathrm{C}$, foram caracterizados por meio da avaliação da absorção de água, porosidade aparente, massa específica aparente, expansão por umidade e resistência à compressão. Em seguida, foram moldados corpos de prova de concreto com agregados leves de argila calcinada produzidos com massas cerâmicas provenientes das cidades de Itu, SP, e Porto Ferreira, SP, com argila expandida e também com brita. Os concretos foram submetidos aos ensaios de massa específica e abatimento do tronco de cone, no estado fresco e de resistência à compressão, resistência à tração por compressão diametral, módulo de deformação e massa específica no estado endurecido. Os resultados desta pesquisa indicam a viabilidade técnica da produção de agregados leves de argila calcinada para utilização em concretos, uma vez que o desempenho de concretos produzidos com agregados leves de argila calcinada é semelhante ao de concretos produzidos com argila expandida e basalto.

Palavras-chaves: Massas cerâmicas. Agregados leves de argila calcinada. Concretos leves.

\footnotetext{
Abstract

This paper aims to evaluate the influence of calcined clay lightweight aggregates on the performance of structural concretes. Firstly, soil samples from different places in the state of São Paulo were collected and characterised. After that, calcined clay specimens were made using those soil samples. The specimens made from these ceramic materials, burned at $900{ }^{\circ} \mathrm{C}$, were characterised by assessing water absorption, apparent porosity, specific mass, moisture expansion and compressive strength. After that, concrete specimens were made using calcined clay lightweight aggregates produced with ceramic masses from Itu - SP and Porto Ferreira - SP, expanded clay and basalt. Specimens were characterised by fresh specific mass, slump test (fresh condition), compressive strength, tensile strength, modulus of elasticity and specific mass (cured state). The results indicated the feasibility of producing calcined clay lightweight aggregates for use in concrete, since the performance of concrete produced with calcined clay lightweight aggregates was similar to the performance of concretes produced with expanded clay and basalt.

Keywords: Ceramic masse. Calcined clay lightweight aggregates. Lightweight concrete.
}

Bruno Carlos de Santis Universidade de São Paulo Pirassununga - SP - Brasil

João Adriano Rossignolo Universidade de São Paulo Pirassununga - SP - Brasil

Recebido em 10/03/14

Aceito em 11/09/14 


\section{Introdução}

O concreto com agregados leves, ou concreto leve estrutural, apresenta-se como um material de construção consagrado em todo o mundo, com aplicação em diversas áreas da construção civil. A ampla utilização desse material é particularmente atribuída aos benefícios promovidos pela redução da massa específica do concreto, como a redução de esforços na estrutura das edificações, a economia com formas e cimbramento, e a diminuição dos custos com transporte e montagem de construções pré-fabricadas (ZHANG; GJФRV, 1991; ROSSIGNOLO, 2009).

Contudo, as propriedades dos concretos de cimento Portland estão diretamente relacionadas com o desempenho de suas fases constituintes, assim como da ligação entre elas, característica intrínseca aos materiais heterogêneos. Como os agregados graúdos usualmente representam mais de $50 \%$ do volume dos concretos convencionais, sua substituição por agregados leves promove alterações consideráveis nas propriedades dos concretos, que dependem, essencialmente, das características desses agregados. A resistência à compressão, a massa específica, a relação entre essas duas propriedades (denominada Fator de Eficiência) e o módulo de deformação são os parâmetros mais utilizados na caracterização dos concretos leves estruturais, estando diretamente relacionados com o tipo, as propriedades e a granulometria do agregado leve utilizado (ROSSIGNOLO, 2009).

Atualmente, os agregados leves de argila expandida aparecem como uma das poucas opções de agregados leves nacionais para a produção de concretos, tornando sua utilização modesta ante seu potencial de aplicação. Sua utilização estáconcentrada no estado de São Paulo e em estados vizinhos, dada a localização da fábrica de argila expandida Cinexpan, em Várzea Paulista, SP, único fabricante de agregados leves no país. Por se tratar de uma única empresa produtora, o alto custo do transporte a longas distâncias dificulta a disseminação dessa tecnologia por todo o território nacional (ROSSIGNOLO, 2009; TEZUKA, 1973).

Uma alternativa para a disseminação da tecnologia do concreto leve estrutural por todo o país seria a produção de agregados leves de argila calcinada, utilizando a cerâmica vermelha, já que existem cerca de 11 mil empresas produtoras de cerâmica vermelha espalhadas por todo o território nacional, as quais, com pequenas modificações em suas linhas de produção, poderiam produzir agregados leves de argila calcinada como mais um de seus produtos comerciais (SERVIÇO..., 2008).

Estudos preliminares indicam a viabilidade de produção e utilização desse tipo de agregado leve na construção civil, utilizando-se os polos produtivos de cerâmica vermelha espalhados por todo o Brasil (SANTIS, 2012; CABRAL, 2005).

Assim, este trabalho tem como objetivo a análise da influência de agregados leves de argila calcinada nas propriedades mecânicas de concretos estruturais, quando comparados aos concretos produzidos com agregados leves de argila expandida e com agregados convencionais de basalto.

\section{Materiais e métodos}

Para a presente pesquisa, foram coletadas matérias-primas (solos) de cinco diferentes empresas fabricantes de produtos cerâmicos no estado de São Paulo, em cinco diferentes cidades: Tambaú, Porto Ferreira, Ubarana, Leme e Itu. Nas amostras de solo coletadas in natura foram realizadas as seguintes análises: determinação dos limites de liquidez (LL) (ABNT, 1984a) e de plasticidade (LP) (ABNT, 1984b), análise granulométrica (ABNT, 1984c) e determinação da massa específica dos sólidos (ABNT, 1984d).

As amostras de solo foram submetidas também aos ensaios de difração de raios $\mathrm{X}$ (DRX), à espectrometria de fluorescência de raios X (FRX) eàs análises térmicas diferencial (ATD) $\mathrm{e}$ termogravimétrica (TG).

Para a determinação da umidade natural das amostras de solo, elas foram destorroadas, moídas (com diâmetro final das partículas inferior a 0,2 $\mathrm{mm})$ e secas em estufa, à temperatura de $100^{\circ} \mathrm{C}$.

A partir dos valores de quantidade de água contida em cada uma das amostras, assim como seus limites de liquidez e plasticidade, as massas para extrusão foram preparadas adicionando-se quantidades de água que conferiam consistência próxima a seus limites de plasticidade, como ilustra a Tabela1.

As massas cerâmicas foram extrudadas em uma maromba de escala laboratorial produzida pela empresa Indústria de Marombas Gelenski Ltda., modelo MVIG-05. Para a extrusão, utilizou-se boquilha de formato cilíndrico, com diâmetro de $15 \mathrm{~mm}$. Após a extrusão, os corpos de prova foram cortados em tamanhos de $10 \mathrm{~cm}$ de comprimento.

22 Santis, B. C. de; Rossignolo, J. A. 
Tabela 1 - Limites de plasticidade (LP) das amostras de solo e umidade utilizada para extrusão dos corpos de prova

\begin{tabular}{cccccc}
\hline & Ubarana & Porto & Itu & Tambaú & Leme \\
\hline $\mathbf{L P}$ & 19,1 & 30,7 & 21,7 & 28,1 & 25,9 \\
$\mathbf{W}(\boldsymbol{\%})^{\mathbf{1}}$ & 5,8 & 4,7 & 5,0 & 5,0 & 2,4 \\
$\mathbf{W}_{\mathbf{e}}(\boldsymbol{\%})^{\mathbf{2}}$ & 19,4 & 27,5 & 18,2 & 31,6 & 27,8 \\
\hline
\end{tabular}

Nota: (1) Umidade das amostras de solo; e (2) Umidade das amostras para a extrusão.

Os corpos de prova permaneceram em estufa ventilada, a uma temperatura de $60{ }^{\circ} \mathrm{C}$, por um período de $72 \mathrm{~h}$. Em seguida, foram queimados em uma mufla da marca Jung, modelo 10013, com potência de $7 \mathrm{KW}$, com temperatura de $900{ }^{\circ} \mathrm{C}$. A queima foi realizada com rampa de aquecimento de $4{ }^{\circ} \mathrm{C} / \mathrm{min}$ e de resfriamento de $6{ }^{\circ} \mathrm{C} / \mathrm{min}$, tendo as peças ficado submetidas à temperatura máxima $\left(900^{\circ} \mathrm{C}\right)$ por $60 \mathrm{~min}$.

Após a queima, os corpos de prova foram submetidos aos ensaios de absorção de água (após imersão de 24 h) e massa específica aparente (após imersão por 48 h) (ABNT, 2009), porosidade aparente, expansão por umidade (ABNT, 1997) e resistência à compressão (adaptado de ABNT, 2007). O ensaio de resistência à compressão foi realizado mediante uma adaptação do ensaio de resistência à compressão em corpos de prova cilíndricos de concreto; por isso, os corpos de prova cerâmicos foram cortados com comprimento de $3 \mathrm{~cm}$.

Com base nos resultados obtidos nos ensaios realizados nos corpos de prova cerâmicos, foram escolhidas as amostras de solo (argila) de Porto Ferreira e Itu para a produção de agregados leves de argila calcinada, uma vez que os corpos de prova cerâmicos confeccionados com argila de Itu (fábrica com alto controle de qualidade) apresentaram-se mais densos e mais resistentes que os corpos de prova cerâmicosconfeccionados com argila de Porto Ferreira (fábrica com baixo controle de qualidade). Essa escolha deu-se também porque os corpos de prova produzidos com essas massas cerâmicas apresentaram valores distintos de resistência à compressão, e os corpos de prova cerâmicos produzidos com massa cerâmica de Itu apresentaram valores de resistência à compressão superiores aos produzidos com massa cerâmica de Porto Ferreira.

Os agregados leves de argila calcinada foram produzidos no Laboratório de Construções Rurais e Ambientais da FZEA/USP, na cidade de Pirassununga, SP, da mesma forma que os corpos de prova de argila calcinada. Após a extrusão, a argila extrudada foi cortada em seu tamanho final (aproximadamente $15 \times 15 \mathrm{~mm}$ ), formando-se os agregados leves de argila, que foram queimados utilizando-se o mesmo procedimento utilizado para os corpos de prova cerâmicos.

Depois de confeccionados os agregados de cerâmica vermelha, foram produzidos os concretos, com agregados leves de argila calcinada, argila expandida e brita basáltica $n^{\circ} 1$. Os corpos de prova foram confeccionados no Laboratório de Construção Civil (LCC) do Instituto de Arquitetura e Urbanismo de São Carlos, SP - USP. A Tabela 2 apresenta as características dos quatro tipos de agregados utilizados.

Conhecendo-se as características de cada um dos agregados, procurou-se manter em um mesmo patamar os consumos de cimento e areia para os quatro tipos de concreto, assim como uma relação água/cimento de 0,5 e o volume dos agregados graúdos para todos os corpos de prova, como ilustra a Tabela 3 .

A mistura dos materiais foi realizada utilizando-se uma betoneira, e a moldagem das formas deu-se com o auxílio de uma mesa vibratória. Para cada tipo de concreto, foram confeccionados 23 corpos de prova cilíndricos com $100 \mathrm{~mm}$ de diâmetro e $200 \mathrm{~mm}$ de altura. Os concretos foram e secos no ambiente do laboratório por 24 h. Após esse período, foram desformados e submetidos ao processo de cura, em uma câmara úmida com umidade variando de $90 \%$ a $95 \%$ e temperatura variando de $20^{\circ} \mathrm{C} \mathrm{a} 23^{\circ} \mathrm{C}$, até atingirem a idade de 28 dias. Transcorrido esse período, foram transferidos para uma sala climatizada, com temperatura variando de $22{ }^{\circ} \mathrm{C}$ a $26^{\circ} \mathrm{C}$ e umidade variando de $62 \%$ a $78 \%$, onde permaneceram até 91 dias de idade.

No estado fresco, os concretos foram submetidos aos ensaios de massa específica (ABNT, 2008) e abatimento do tronco de cone (ABNT, 1998); e, no estado endurecido, foram submetidos aos ensaios de resistência à compressão (ABNT, 2007), resistência à tração por compressão diametral (ABNT, 2011), módulo de deformação e massa específica (ABNT, 2005). 
Tabela 2-Características físicas dos agregados graúdos utilizados na produção dos concretos

\begin{tabular}{ccccc}
\hline Agregado & $\begin{array}{c}\text { Massa unitária } \\
\text { no estado solto } \\
\left(\mathbf{k g} / \mathbf{m}^{\mathbf{3}}\right)\end{array}$ & $\begin{array}{c}\text { Massa específica } \\
\text { saturada }\left(\mathbf{k g} / \mathbf{m}^{\mathbf{3}}\right)\end{array}$ & $\begin{array}{c}\text { Massa específica } \\
\text { aparente }\left(\mathbf{k g} / \mathbf{m}^{\mathbf{3}}\right)\end{array}$ & $\begin{array}{c}\text { Resistência à } \\
\text { compressão } \\
(\mathbf{M P a})\end{array}$ \\
\hline $\begin{array}{c}\text { Argila calcinada } \\
\text { de Itu }\end{array}$ & 1066 & 2129 & 1791 & 39,50 \\
$\begin{array}{c}\text { Brita n } \\
\text { ( } 1\end{array}$ & 1543 & 2930 & 2934 & - \\
$\begin{array}{c}\text { Argila calcinada } \\
\text { de Porto Ferreira } \\
\text { Argila }\end{array}$ & 965 & 2039 & 1555 & 18,00 \\
expandida & 503 & 947 & 975 & - \\
\hline
\end{tabular}

Nota: *Método adaptado da NBR 5739, para corpos de prova cerâmicos cilíndricos com base de $15 \mathrm{~mm}$ e altura de 30 $\mathrm{mm}$.

Tabela 3-Dosagem dos materiais para a produção dos concretos: consumo real de cimento, areia, agregado e água

\begin{tabular}{ccccc}
\hline CP & Cimento (kg) & Areia (kg) & $\begin{array}{c}\text { Agregado } \\
(\mathbf{k g})\end{array}$ & $\begin{array}{c}\text { Relação } \\
\text { água/cimento }\end{array}$ \\
\hline Brita n $^{\mathbf{0}} 1$ & 387,53 & 968,84 & 821,58 & 0,5 \\
Argila expandida & 377,40 & 943,51 & 271,73 & 0,5 \\
Argila calcinada de Itu & 389,17 & 972,92 & 537,06 & 0,5 \\
Argila calcinada de Porto Ferreira & 383,94 & 959,84 & 479,92 & 0,5 \\
\hline
\end{tabular}

\section{Resultados e discussões}

A apresentação dos resultados está dividida em duas etapas. A primeira consiste na caracterização das matérias-primas (argila) e dos corpos de prova cerâmicos; e a segunda, na caracterização dos concretos.

\section{Análise das amostras de solo e corpos de prova cerâmicos}

A Tabela 4 apresenta os valores dos limites de liquidez, plasticidade, índice de plasticidade e massa específica das amostras de solo analisadas. Os valores do limite de liquidez das amostras variaram de $48,8 \%$ a $67,0 \%$. Já os valores do limite de plasticidade das matérias-primas analisadas variaram de $19,1 \%$ a $30,7 \%$, conferindo às amostras índices de plasticidade (IP) entre $18,1 \%$ e $38,9 \%$, o que indica que todas as amostras analisadas podem ser classificadas como altamente plásticas (índice de plasticidade superior a 15\%) (PEREZ et al., 2010).

Ainda de acordo com Pérez et al. (2010), para a moldagem por extrusão de peças cerâmicas, os valores adequados para o limite de plasticidade e para o índice de plasticidade são, respectivamente, de $15 \%$ a $25 \%$ e de $10 \%$ a $35 \%$. As amostras de Ubarana e de Itu apresentaram valores de limites de plasticidade compreendidos entre $15 \%$ e $25 \%$ ( $19,1 \%$ e $21,7 \%$ respectivamente). Com relação ao índice de plasticidade, as amostras de Porto
Ferreira, Leme e Itu foram as únicas que apresentaram valores compreendidos entre $10 \%$ e $35 \%(18,1 \%, 32,1 \%$ e $27,3 \%$ respectivamente). Portanto, a única amostra que apresentou limite de plasticidade e índice de plasticidade compreendidos entre os valores adequados para a moldagem por extrusão foi a de Itu $(21,7 \%$ e $27,3 \%$ respectivamente)

Os valores das massas específicas dos solos também são apresentados na Tabela 4. O menor valor de massa específica encontrado foi na amostra de Tambaú $\left(2,360 \mathrm{~g} / \mathrm{cm}^{3}\right)$, e o maior, na amostra de Ubarana $\left(2,695 \mathrm{~g} / \mathrm{cm}^{3}\right)$. Como a massa específica dos solos está diretamente ligada à massa específica aparente das peças queimadas, as peças conformadas com as amostras de maior massa específica dos solos poderão apresentar maior massa específica aparente, devido à maior densificação das massas durante a queima, proporcionando um produto final mais pesado e resistente, com baixa porosidade aparente.

$\mathrm{Na}$ Tabela 5 apresenta-se o resultado da análise granulométrica das amostras de solo. Em todas as amostras analisadas, os teores de argila são predominantes, e a amostra de Ubarana, apesar de ter alto teor de argila em sua composição (53\%), apresentou também um alto teor de areia (28\%), o que contribuiu para o baixo valor do limite de plasticidade dessa amostra $(19,1 \%)$, já que a areia é dos principais materiais desplastificantes (PRACIDELLI; MELCHIADES, 1997).

24 Santis, B. C. de; Rossignolo, J. A. 
As amostras de Porto Ferreira e Leme apresentaram teores semelhantes de argila em suas composições ( $48 \%$ e $48,5 \%$ respectivamente), o que contribuiu para que as duas amostras fossem conformadas com quantidades de água muito semelhantes $(27,5 \%$ e $27,8 \%)$, mesmo a amostra de Porto Ferreira apresentando um limite de plasticidade superior à amostra de Leme. $\mathrm{O}$ fato de todas as amostras apresentarem predominância de grãos finos (argila e silte) comprova suas características plásticas.

Analisando-se a Tabela 6, que apresenta a composição química das amostras de solo, percebe-se que todas as amostras apresentam predominância de $\mathrm{SiO}_{2}$ e $\mathrm{Al}_{2} \mathrm{O}_{3}$ em sua composição, o que pode conferir às peças queimadas maiores valores de resistência à compressão, uma vez que massas cerâmicas com altos teores de $\mathrm{SiO}_{2}$ e $\mathrm{Al}_{2} \mathrm{O}_{3}$ podem apresentar maior possibilidade de vitrificação.
A presença de quantidades superiores a $1 \%$ de dióxido titânio $\left(\mathrm{TiO}_{2}\right)$ nas amostras de solo de Itu e Ubarana pode ser responsável pela cor acinzentada delas, da mesma forma que a presença de grandes quantidades de óxido de ferro III $\left(\mathrm{Fe}_{2} \mathrm{O}_{3}\right)$ nas amostras de Tambaú, Porto Ferreira e Itu confere a elas coloração avermelhada (SANTOS, 1989a).

A perda ao fogo das amostras analisadas variou de $4,64 \%$, para a amostra de Leme, a $10,96 \%$, para a amostra de Ubarana. A perda ao fogo indica uma perda de massa em função do aumento da temperatura e dá-se, principalmente, pela umidade das massas, além da perda de hidroxilas dos hidróxidos, como $\mathrm{Al}(\mathrm{OH})_{3}$ e $\mathrm{Fe}(\mathrm{OH})_{3}$. Isso explica a maior perda ao fogo observada na amostra de Ubarana, assim como a menor perda ao fogo observada na amostra de Leme (GRUN, 2007; SANTOS, 1989b).

A Tabela 7 apresenta os valores de absorção de água e porosidade aparente dos corpos de prova cerâmicos.

Tabela 4- Limites de liquidez, plasticidade, índice de plasticidade e massa específica das amostras de solo

\begin{tabular}{ccccc}
\hline Amostra & $\mathbf{L} \mathbf{L}^{(\mathbf{1})}(\boldsymbol{\%})$ & $\mathbf{L P}^{(\mathbf{2})}(\boldsymbol{\%})$ & $\mathbf{I P}^{(\mathbf{3})}(\boldsymbol{\%})$ & $\mathbf{\rho}_{\mathbf{s}}^{(\mathbf{4})}\left(\mathbf{g} / \mathbf{c m}^{\mathbf{3}}\right)$ \\
\hline Tambaú & 67,0 & 28,1 & 38,9 & 2,360 \\
Porto Ferreira & 48,8 & 30,7 & 18,1 & 2,640 \\
Ubarana & 57,5 & 19,1 & 38,4 & 2,695 \\
Leme & 58,0 & 25,9 & 32,1 & 2,675 \\
Itu & 49,0 & 21,7 & 27,3 & 2,585 \\
\hline
\end{tabular}

Nota: (1) Limite de liquidez; (2) Limite de plasticidade; (3) Índice de plasticidade; e (4) Massa específica dos sólidos.

Tabela 5- Composição granulométrica das amostras de solo

\begin{tabular}{ccccccc}
\hline Amostra & $\begin{array}{c}\text { Argila } \\
(\boldsymbol{\%})\end{array}$ & Silte $(\boldsymbol{\%})$ & $\begin{array}{c}\text { Areia fina } \\
(\boldsymbol{\%})\end{array}$ & $\begin{array}{c}\text { Areia } \\
\text { média } \\
(\boldsymbol{\%})\end{array}$ & $\begin{array}{c}\text { Areia } \\
\text { grossa } \\
(\boldsymbol{\%})\end{array}$ & $\begin{array}{c}\text { Pedregulho } \\
(\boldsymbol{\%})\end{array}$ \\
\hline Tambaú & 61 & 34 & 2 & 1 & 1 & 1 \\
Porto Ferreira & 48 & 28 & 17 & 6 & 1 & 0 \\
Ubarana & 53 & 19 & 24 & 3 & 1 & 0 \\
Leme & 48,5 & 37,5 & 10 & 3 & 1 & 0 \\
Itu & 50 & 31 & 6 & 9 & 4 & 0 \\
\hline
\end{tabular}

Tabela 6- Composição química das amostras de solo

\begin{tabular}{|c|c|c|c|c|c|c|c|c|c|c|c|}
\hline Amostra & $\begin{array}{c}\mathrm{SiO}_{2} \\
(\%)\end{array}$ & $\begin{array}{c}\mathrm{TiO}_{2} \\
(\%)\end{array}$ & $\begin{array}{c}\mathrm{Al}_{2} \mathrm{O}_{3} \\
(\%)\end{array}$ & $\begin{array}{c}\mathrm{Fe}_{2} \mathrm{O}_{3} \\
(\%)\end{array}$ & $\begin{array}{c}\mathrm{MnO} \\
(\%)\end{array}$ & $\begin{array}{c}\text { MgO } \\
(\%)\end{array}$ & $\begin{array}{c}\mathrm{CaO} \\
(\%)\end{array}$ & $\begin{array}{c}\mathrm{Na}_{2} \mathbf{O} \\
(\%)\end{array}$ & $\begin{array}{l}\mathrm{K}_{2} \mathrm{O} \\
(\%)\end{array}$ & $\begin{array}{c}\mathbf{P}_{2} \mathbf{O}_{5} \\
(\%)\end{array}$ & $\begin{array}{c}\text { Perda } \\
\text { ao } \\
\text { fogo* } \\
(\%)\end{array}$ \\
\hline Tambaú & 66,7 & 0,904 & 15,64 & 6,32 & 0,057 & 1,36 & 0,32 & 0,12 & 2,40 & 0,119 & 6,04 \\
\hline $\begin{array}{c}\text { Porto } \\
\text { Ferreira }\end{array}$ & 59,5 & 0,875 & 17,38 & 7,43 & 0,074 & 2,94 & 0,58 & 1,23 & 3,86 & 0,183 & 5,42 \\
\hline Ubarana & 60,3 & 1,350 & 21,10 & 3,85 & 0,034 & 0,28 & 0,12 & 0,13 & 1,65 & 0,120 & 10,96 \\
\hline Leme & 68,1 & 0,614 & 14,42 & 4,88 & 0,088 & 1,81 & 0,32 & 0,31 & 4,20 & 0,110 & 4,64 \\
\hline Itu & 65,1 & 1,282 & 16,84 & 6,81 & 0,066 & 0,44 & 0,23 & 0,07 & 0,94 & 0,088 & 7,68 \\
\hline
\end{tabular}

Nota: *Perda ao fogo realizada a temperatura de $1.000{ }^{\circ} \mathrm{C}$. 
Tabela 7 - Absorção de água e porosidade aparente dos corpos de prova de argila calcinada

\begin{tabular}{c|c|c|c|c}
\hline Local & $\begin{array}{c}\text { Absorção } \\
\text { de água (\%) }\end{array}$ & $\begin{array}{c}\text { Desvio } \\
\text { padrão }\end{array}$ & $\begin{array}{c}\text { Porosidade } \\
\text { aparente (\%) }\end{array}$ & $\begin{array}{c}\text { Desvio } \\
\text { padrão }\end{array}$ \\
\hline Tambaú & 20,23 & 0,61 & 34,16 & 0,67 \\
Porto Ferreira & 24,18 & 0,36 & 37,59 & 0,31 \\
Ubarana & 16,34 & 0,14 & 29,16 & 0,20 \\
Leme & 18,73 & 0,26 & 31,75 & 0,34 \\
Itu & 16,55 & 0,25 & 29,64 & 0,45 \\
\hline
\end{tabular}

Os valores de absorção de água dos corpos de prova queimados variaram entre $16,34 \%$ e $24,18 \%$, valores esses abaixo de $25 \%$, valor máximo de absorção de água para tijolos maciços e blocos de cerâmica vermelha. No entanto, considerando a produção de agregados para concreto, esses valores são considerados altos, já que a absorção de água da argila expandida (imersa em água por $24 \mathrm{~h})$ não ultrapassa o valor de $10 \%$ (ROSSIGNOLO, 2009).

Os corpos de prova de Ubarana e Itu foram os que apresentaram menores valores de absorção de água. Esse fato pode ser um indício de que a queima foi bem feita e de que os corpos de prova tiveram boa densificação durante a queima, consequência dos valores de massa específica aparente dos corpos de prova, os maiores entre os estudados $\left(1,785 \mathrm{~g} / \mathrm{cm}^{3}\right.$ e $1,791 \mathrm{~g} / \mathrm{cm}^{3}$ respectivamente), conforme ilustra a Figura 1.

Além disso, os corpos de prova de Ubarana e Itu apresentaram as menores quantidades de material fundente $\left(\mathrm{Fe}_{2} \mathrm{O}_{3}+\mathrm{MgO}+\mathrm{CaO}+\mathrm{Na}_{2} \mathrm{O}+\mathrm{K}_{2} \mathrm{O}\right)$ em suas composições $\quad(6,03 \%$ e $8,49 \%$ respectivamente) e as menores quantidades de água para conformação $(19,4 \%$ e $18,2 \%$ respectivamente).

Já as amostras de Ubarana e Itu foram as que apresentaram os menores valores de porosidade aparente, $29,16 \%$ e $29,64 \%$ respectivamente, o que confirma o dado apresentado na Tabela 7, mostrando que as duas amostras foram também as que apresentaram menores valores de absorção de água, $16,34 \%$ e $16,55 \%$ respectivamente.

Os dados de expansão por umidade, massa específica aparente e resistência à compressão dos corpos de prova de argila calcinada são apresentados na Tabela 8. Todas as amostras apresentaram baixos valores de expansão por umidade, o que pode ser um indício de que a expansão por umidade dos agregados leves de argila calcinada não alterará as características finais dos concretos. $\mathrm{O}$ valor negativo da expansão por umidade apresentado pela amostra de Itu ($0,86 \%)$ e de Ubarana $(-0,03 \%)$ pode ser atribuído ao elevado desvio padrão das medidas.

A massa específica aparente está ligada à porosidade aparente e à absorção de água das peças queimadas. Quanto maior o valor da massa específica aparente da peça queimada, mais densa é essa peça, apresentando menores valores de porosidade aparente e absorção de água. Dessa forma, observa-se que as amostras que apresentaram maiores valores de massas específicas aparentes foram as de Itu e Ubarana $\left(1,791 \mathrm{~g} / \mathrm{cm}^{3}\right.$ e $1,785 \mathrm{~g} / \mathrm{cm}^{3}$ respectivamente), que apresentaram também os menores valores de absorção de água $(16,55 \%$ e $16,34 \%$ respectivamente) e porosidade aparente $(29,64 \%$ e $29,16 \%$ respectivamente). Os corpos de prova de Porto Ferreira apresentaram o menor valor de massa específica aparente $(1,555 \mathrm{~g} / \mathrm{cm})$ e os maiores valores de absorção de água e porosidade aparente $(24,18 \%$ e $37,59 \%$ respectivamente $)$ como ilustra a Figura 1.

No caso de agregados leves de argila expandida, essa afirmação não se aplica, uma vez que a argila expandida caracteriza-se por um produto de baixa massa especifica e alta porosidade, mas com baixos valores de absorção de água, uma vez que a porosidade da argila expandida dá-se apenas em seu interior, sem conexão com suas extremidades, o que dificulta a penetração da água.

Para a produção de concretos, a massa específica dos agregados é de fundamental importância, já que influencia diretamente no valor da massa específica. Os valores das massas específicas observadas para as peças de cerâmica vermelha encontram-se em um patamar intermediário, quando comparados aos das massas específicas do basalto $\left(2,95 \mathrm{~g} / \mathrm{cm}^{3}\right)$ e da argila expandida com dimensões de $15 \mathrm{~mm}$ a $22 \mathrm{~mm}\left(0,7 \mathrm{~g} / \mathrm{cm}^{3}\right)$ (ROSSIGNOLO, 2009). 
Tabela 8 - Valores de expansão por umidade, de massa específica aparente e de resistência à compressão dos corpos de prova queimados

\begin{tabular}{c|c|c|c|c|c|c}
\hline Local & $\begin{array}{c}\text { Expansão } \\
\text { por umidade } \\
(\boldsymbol{\%})\end{array}$ & $\begin{array}{c}\text { Desvio } \\
\text { padrão }\end{array}$ & $\begin{array}{c}\text { Massa } \\
\text { específica } \\
\text { aparente } \\
\left(\mathbf{g} / \mathbf{c m}^{\mathbf{3}}\right)\end{array}$ & $\begin{array}{c}\text { Desvio } \\
\text { padrão }\end{array}$ & $\begin{array}{c}\text { Resistência à } \\
\text { compressão } \\
\text { (MPa) }\end{array}$ & $\begin{array}{c}\text { Desvio } \\
\text { padrão }\end{array}$ \\
\hline Tambaú & 0,02 & 0,10 & 1,689 & 0,022 & 43,5 & 10,9 \\
Porto Ferreira & 0,11 & 0,08 & 1,555 & 0,012 & 18,0 & 4,1 \\
Ubarana & $-0,03$ & 0,08 & 1,785 & 0,004 & 55,8 & 11,4 \\
Leme & 0,02 & 0,06 & 1,695 & 0,009 & 38,6 & 3,4 \\
Itu & $-0,86$ & 0,84 & 1,791 & 0,006 & 39,5 & 5,4 \\
\hline
\end{tabular}

Figura 1 - Massa específica aparente, porosidade aparente e absorção de água dos corpos de prova queimados

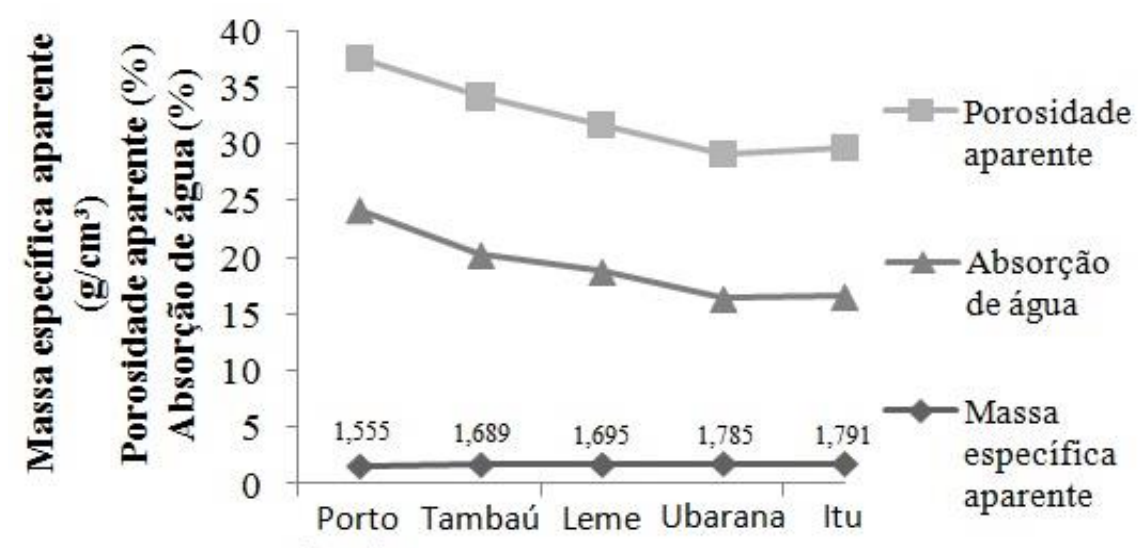

Ferreira

\section{Amostras}

Figura 2 - Resistência à compressão das peças queimadas em função de suas massas específicas aparentes

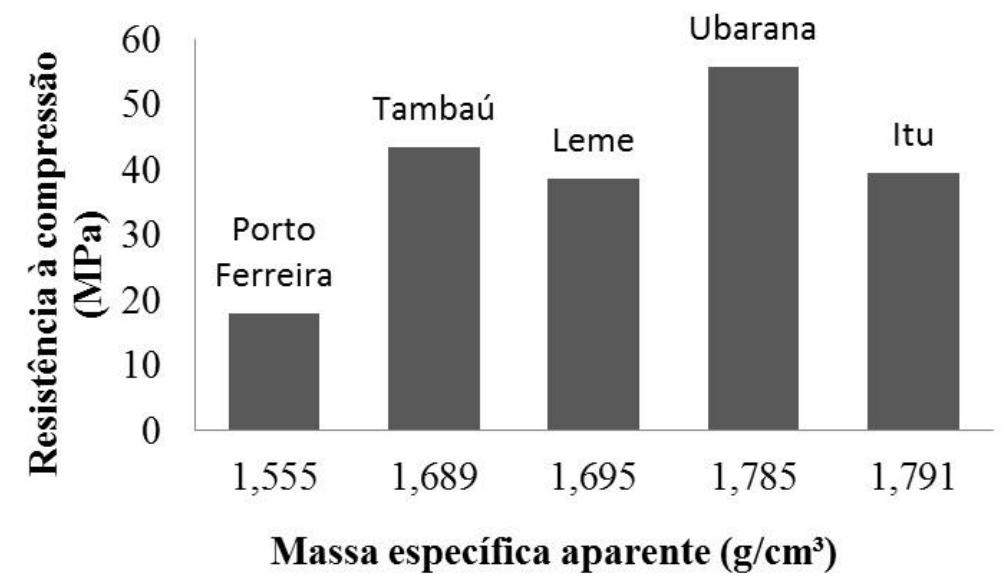

A amostra de Ubarana, que apresentou um dos maiores valores de massa específica entre todas as amostras, teve o maior valor de resistência à compressão $(55,8 \mathrm{MPa})$, o que pode estar ligado à densificação da peça, já que ela apresentou o menor valor de porosidade aparente $(29,16 \%)$ entre todas as amostras analisadas. Da mesma forma, por apresentar a menor massa específica $\left(1,555 \mathrm{~g} / \mathrm{cm}^{3}\right)$ e a maior porosidade aparente $(37,59 \%)$, a amostra de Porto Ferreira teve também a menor resistência à compressão (18,0 MPa).

Analisando-se a Figura 2, percebe-se que o aumento do valor da massa específica dos corpos 
de prova ocasiona aumento nos valores da resistência à compressão, com exceção para a amostra de Itu, que, apesar de apresentar valores de massa específica semelhantes aos observados para a amostra de Ubarana, registrou valores de resistência à compressão menores. Esse comportamento pode ser explicado em decorrência das especificidades da granulometria e composição química da matéria-prima dessas massas cerâmicas, assim como pelos elevados valores do desvio padrão da resistência à compressão dos corpos de prova de Itu e Ubarana.

\section{Análise dos corpos de prova de concreto}

Para a análise dos concretos, foram produzidos corpos de prova com agregados leves de Itu e Porto Ferreira, argila expandida e brita.

A Tabela 9 apresenta os valores das propriedades do concreto no estado fresco.

Analisando-se a Tabela 9, percebe-se que os valores de massa específica dos concretos no estado fresco variaram entre $2.386 \mathrm{~kg} / \mathrm{m}^{3}$ para os concretos produzidos com brita como agregado e $1.766 \mathrm{~kg} / \mathrm{m}^{3}$ para os produzidos com agregados de argila expandida. Os concretos produzidos com os agregados leves de argila calcinada de Itu e de Porto Ferreira apresentaram massa específica no estado fresco iguais a $2.151 \mathrm{~kg} / \mathrm{m}^{3}$ e a $2.124 \mathrm{~kg} / \mathrm{m}^{3}$ respectivamente, com uma redução em massa de $9,85 \%$ e $10,98 \%$ respectivamente, quando comparados aos concretos produzidos com brita, permanecendo em um patamar intermediário entre os produzidos com brita e os produzidos com argila expandida.

Os valores de resistência à compressão dos concretos são apresentados na Tabela 10.

De acordo com a Tabela 10, aos 7 dias de idade, os valores de resistência dos corpos de prova são muito próximos, uma vez que, nessa idade, a pasta de cimento ainda não atingiu sua resistência máxima, e, com isso, os agregados apresentam menos influência na resistência dos concretos do que em idades mais avançadas.

Já aos 91 dias de idade, quando a pasta de cimento, areia e água já atingiu boa parte de sua capacidade resistente, os concretos confeccionados com brita (agregado com valor de resistência à compressão da ordem de $120 \mathrm{Mpa}$ a $150 \mathrm{MPa}$ ) apresentaram valor de resistência à compressão $(42,77 \mathrm{MPa})$ superior ao observado para os concretos confeccionados com agregados leves de argila calcinada de Porto Ferreira (agregado com valor de resistência à compressão igual a 18,0 $\mathrm{MPa}$ ), que apresentaram valor de resistência à compressão de 25,82 $\mathrm{MPa}$.

Portanto, a resistência dos concretos aumenta com o aumento da idade deles, uma vez que a resistência da pasta de cimento também aumenta com o passar do tempo.

Ainda de acordo com a Tabela 10, percebe-se que em todas as idades os corpos de prova produzidos com agregados de argila expandida e agregados leves de argila calcinada de Itu apresentaram valores muito próximos de resistência à compressão, sendo eles inferiores aos valores apresentados pelos corpos de prova produzidos com brita (agregado mais resistente entre os analisados) e superiores aos valores apresentados pelos corpos de prova produzidos com agregados leves de argila calcinada de Porto Ferreira (agregado menos resistente entre os analisados).

Os valores de massa específica aparente e fator de eficiência $(\mathrm{Fe})^{1}$ dos corpos de prova são apresentados na Tabela 11.

Analisando-se a Tabela 11, percebe-se que os agregados têm grande influência na massa específica dos concretos, uma vez que os concretos confeccionados com agregados mais densos (brita) apresentaram massa específica maior do que os concretos confeccionados com agregados menos densos (argila expandida).

Ainda analisando a Tabela 11, percebe-se que os concretos confeccionados com os agregados de Porto Ferreira e Itu apresentam valores de massa específica aparente em um patamar intermediário quando comparados aos dos concretos confeccionados com argila expandida e brita, sendo a redução de massa para os corpos de prova com agregados de itu de $12,8 \%$, e para os corpos de prova com agregados de Porto Ferreira, de $15,2 \%$, quando comparados aos corpos de prova confeccionados com brita.

$\mathrm{O}$ fator de eficiência $(\mathrm{Fe})$ dos concretos variou de 13,62 MPa.dm $3 / \mathrm{kg}$, para os corpos de prova produzidos com os agregados de Porto Ferreira, a 19,14 MPa.dm $3 / \mathrm{kg}$, para os corpos de prova produzidos com brita.

Os valores da resistência à tração por compressão diametral dos corpos de prova são apresentados na Tabela 12.

${ }^{1}$ Fator de eficiência corresponde à relação direta entre a resistência à compressão e a massa específica dos concretos.

28 Santis, B. C. de; Rossignolo, J. A. 
Tabela 9 - Propriedades dos corpos de prova de concreto no estado fresco

\begin{tabular}{cccc}
\hline CP & $\begin{array}{c}\text { Massa específica } \\
\left(\mathbf{k g} / \mathbf{m}^{\mathbf{3}}\right)\end{array}$ & $\begin{array}{c}\text { Slump } \\
(\mathbf{m m})\end{array}$ & $\begin{array}{c}\text { Teor de ar } \\
\text { incorporado (\%) }\end{array}$ \\
\hline Brita no 1 & 2.386 & 40 & 2,03 \\
Argila expandida & 1.766 & 50 & 4,59 \\
Argila calcinada de Itu & 2.151 & 45 & 2,66 \\
$\begin{array}{c}\text { Argila calcinada de } \\
\text { Porto Ferreira }\end{array}$ & 2.124 & 50 & 2,82 \\
\hline
\end{tabular}

Tabela 10 - Valores de resistência à compressão dos concretos

\begin{tabular}{|c|c|c|c|c|c|c|}
\hline \multirow[b]{2}{*}{ CP } & \multicolumn{6}{|c|}{ Resistência à compressão (MPa) } \\
\hline & 7 dias & $\begin{array}{l}\text { Desvio } \\
\text { padrão }\end{array}$ & 28 dias & $\begin{array}{l}\text { Desvio } \\
\text { padrão }\end{array}$ & 91 dias & Desvio padrão \\
\hline Brita no 1 & 25,55 & 1,15 & 34,07 & 1,38 & 42,77 & 1,03 \\
\hline $\begin{array}{c}\text { Argila } \\
\text { expandida }\end{array}$ & 20,32 & 0,58 & 23,68 & 0,59 & 28,08 & 0,71 \\
\hline $\begin{array}{c}\text { Argila calcinada } \\
\text { de Itu }\end{array}$ & 18,95 & 0,68 & 23,94 & 0,96 & 29,70 & 0,72 \\
\hline $\begin{array}{c}\text { Argila calcinada } \\
\text { de Porto } \\
\text { Ferreira }\end{array}$ & 16,22 & 0,86 & 19,79 & 1,35 & 25,82 & 1,24 \\
\hline
\end{tabular}

Tabela 11 - Massa específica aparente e fator de eficiência dos corpos de prova de concreto (91 dias)

\begin{tabular}{cccc}
\hline CP & $\begin{array}{c}\text { Massa específica } \\
\text { aparente }\left(\mathbf{k g} / \mathbf{m}^{\mathbf{3}}\right)\end{array}$ & $\begin{array}{c}\text { Desvio } \\
\text { padrão }\end{array}$ & $\begin{array}{c}\text { Fator de eficiência } \\
(\mathbf{M P a . d m} \mathbf{k g}) \mathbf{1}\end{array}$ \\
\hline Brita no 1 & 2.235 & 12,98 & 19,14 \\
Argila expandida & 1.608 & 12,70 & 17,46 \\
Argila calcinada de Itu & 1.948 & 1,30 & 15,25 \\
$\begin{array}{c}\text { Argila calcinada de } \\
\text { Porto Ferreira }\end{array}$ & 1.896 & 7,05 & 13,62 \\
\hline
\end{tabular}

Tabela 12 - Valores de resistência à tração dos corpos de prova de concreto

\begin{tabular}{cccc}
\hline Corpo de prova & $\begin{array}{c}\text { Resistência à } \\
\text { tração (MPa) }\end{array}$ & $\begin{array}{c}\text { Desvio padrão } \\
(\mathbf{M P a})\end{array}$ & $\begin{array}{c}\text { Resistência à } \\
\text { tração/Resistência à } \\
\text { compressão (28 dias) } \\
(\%)\end{array}$ \\
\hline Brita no 1 & 2,92 & 0,11 & 8,57 \\
Argila expandida & 1,80 & 0,55 & 7,60 \\
Argila calcinada de Itu & 2,29 & 0,61 & 9,57 \\
\hline Argila calcinada de Porto Ferreira & 1,78 & 0,37 & 8,99 \\
\hline
\end{tabular}

Analisando-se a Tabela 12, percebe-se que os valores da relação entre a resistência à tração e a resistência à compressão dos concretos são muito semelhantes, variando de $7,6 \%$, para os concretos confeccionados com agregados de argila expandida, a 9,5\%, para os concretos confeccionados com agregados leves de argila calcinada de Itu, o que é um indício de que os agregados confeccionados com matérias-primas de Porto Ferreira e Itu não alteram os valores da relação "resistência à tração/resistência à compressão" dos concretos, normalmente em torno de $10 \%$.

A Tabela 13 apresenta os valores dos módulos de deformação dos corpos de prova de concreto aos 28 dias de idade. 
Tabela 13 - Módulo de deformação dos corpos de prova de concreto

\begin{tabular}{ccc}
\hline CP & $\begin{array}{c}\text { Módulo de } \\
\text { deformação (GPa) }\end{array}$ & $\begin{array}{c}\text { Desvio padrão } \\
(\mathbf{G P a})\end{array}$ \\
\hline Brita no 1 & 36,63 & 0,75 \\
Argila expandida & 20,44 & 2,64 \\
Argila calcinada de Itu & 19,48 & 0,51 \\
Argila calcinada de Porto Ferreira & 17,41 & 1,58 \\
\hline
\end{tabular}

Observando-se a Tabela 13, percebe-se que os valores dos módulos de deformação dos concretos com agregados leves foram inferiores aos valores do módulo de deformação dos concretos produzidos com brita, uma vez que os agregados leves apresentaram valores de resistência à compressão e módulo de deformação inferiores aos agregados convencionais (brita).

Isso fica evidente quando se compara o módulo de deformação dos concretos confeccionados com brita e os confeccionados com agregados leves de Porto Ferreira. Os concretos confeccionados com brita apresentaram o maior módulo de deformação entre os analisados (36,63 GPa), e a brita apresentou a maior resistência entre os agregados analisados (na ordem de $120 \mathrm{Mpa}$ a $150 \mathrm{MPa}$ ). Já os concretos confeccionados com agregados leves de argila calcinada de Porto Ferreira apresentaram os menores valores de módulo de deformação $(17,41 \mathrm{GPa})$, assim como os agregados leves de argila calcinada de Porto Ferreira apresentaram os menores valores de resistências à compressão (18,0 MPa).

\section{Conclusões}

Com os resultados obtidos neste trabalho, há indicações de que a produção de agregados leves de argila calcinada para a utilização em concretos estruturais pode ser viável do ponto de vista técnico, uma vez que apresentam características compatíveis com as determinadas para a utilização em concreto estrutural, com grande influência nas características dos concretos e destaque para os aspectos a seguir.

Os corpos de prova cerâmicos apresentaram valores de absorção de água superiores aos observados para a argila expandida (10\%), o que evidencia a necessidade de cuidados especiais quando da utilização de agregados leves de argila calcinada em concretos estruturais, de modo que os agregados não absorvam a água necessária para a hidratação do cimento.

Os concretos produzidos com agregados leves de argila calcinada apresentaram valores de massa específica aparente em um patamar intermediário entre os concretos produzidos com brita e os produzidos com argila expandida, tendo-se observado uma redução em massa de $12,8 \%$ e $15,2 \%$ para os concretos com agregados leves de Itu e Porto Ferreira respectivamente, quando comparados aos concretos com brita.

Os concretos confeccionados com agregados leves de argila calcinada de Itu e de Porto Ferreira atingiram patamares similares de resistência à compressão e módulo de deformação, quando comparados aos valores obtidos para os concretos produzidos com argila expandida. Porém, suas massas específicas aparentes foram superiores às observadas nos concretos com argila expandida.

Os agregados têm influência direta nas propriedades dos concretos, uma vez que os concretos confeccionados com agregados mais densos e mais resistentes apresentaram valores maiores de massa específica e resistência à compressão quando comparados aos concretos confeccionados com agregados menos densos e menos resistentes.

Portanto, agregados leves de argila calcinada mostram-se como possível alternativa para a utilização em concretos estruturais leves, levandose em consideração aspectos técnicos das propriedades mecânicas dos concretos, já que os corpos de prova confeccionados com agregados leves de argila calcinada apresentaram desempenho similar aos corpos de prova confeccionados com argila expandida, além da possibilidade de disseminação dessa tecnologia no país, uma vez que existe grande quantidade de empresas produtoras de cerâmica vermelha espalhadas por todo o território nacional.

\section{Referências}

\section{ASSOCIAÇÃO BRASILEIRA DE NORMAS TÉCNICAS. NBRNM 53: agregado graúdo: determinação de massa específica, massa específica aparente e absorção de água. Rio de Janeiro, 2009.}

\section{ASSOCIAÇÃO BRASILEIRA DE NORMAS} TÉCNICAS. NBRNM 67: concreto: determinação da consistência pelo abatimento do tronco de cone. Rio de Janeiro, 1998. 
ASSOCIAÇÃO BRASILEIRA DE NORMAS TÉCNICAS. NBR 5739: ensaio de compressão de corpos-de-prova cilíndricos de concreto. Rio de Janeiro, 2007.

\section{ASSOCIAÇÃO BRASILEIRA DE NORMAS} TÉCNICAS. NBR 6459: solo: determinação do limite de liquidez. Rio de Janeiro, 1984a.

ASSOCIAÇÃO BRASILEIRA DE NORMAS TÉCNICAS. NBR 6508: grãos de solos que passam na peneira de $4,8 \mathrm{~mm}$ : determinação da massa específica. Rio de Janeiro, 1984d.

ASSOCIAÇÃO BRASILEIRA DE NORMAS TÉCNICAS. NBR 7180: solo: determinação do limite de plasticidade. Rio de Janeiro, 1984b.

ASSOCIAÇÃO BRASILEIRA DE NORMAS TÉCNICAS. NBR 7181: solo: análise granulométrica. Rio de Janeiro, 1984c.

ASSOCIAÇÃO BRASILEIRA DE NORMAS TÉCNICAS. NBR 7222: concreto e argamassa: determinação da resistência à tração por compressão diametral de corpos de prova cilíndricos. Rio de Janeiro, 2011.

\section{ASSOCIAÇÃO BRASILEIRA DE NORMAS} TÉCNICAS. NBR 9778: argamassa e concreto endurecidos: determinação da Absorção de Água, Índice de Vazios e Massa específica. Rio de Janeiro, 2005.

\section{ASSOCIAÇÃO BRASILEIRA DE NORMAS} TÉCNICAS. NBR 9833: concreto fresco: determinação da massa específica e do teor de ar pelo método gravimétrico. Rio de Janeiro, 2008.

\section{ASSOCIAÇÃO BRASILEIRA DE NORMAS} TÉCNICAS. NBR 13818: placas cerâmicas para revestimento: especificação e método de ensaio. Rio de Janeiro, 1997.

CABRAL, G. L. L. Metodologia de Produção e Emprego de Agregados de Argila Calcinada Para Pavimentação.Rio de Janeiro, 2005. 358 f. Dissertação (Mestrado) - Instituto Militar de Engenharia, Rio de Janeiro, 2005.

GRUN, E. Caracterização de Argilas Provenientes de Canelinha/SC e Estudo de Formulações de Massas Cerâmicas.Joinville, 2007. 60 f. Dissertação (Mestrado em Engenharia Civil) - Escola de Engenharia, Universidade do Estado de Santa Catarina, Joinville, 2007.

PÉREZ, C. A. S. et al. Caracterização de Massas Cerâmicas Utilizadas na Indústria de Cerâmica Vermelha em São Domingos do Sul - RS.

Cerâmica Industrial,v. 15, n. 1, p. 38-43, jan./fev. 2010.
PRACIDELLI, S.; MELCHIADES, F. G. Importância da Composição Granulométrica de Massas Para a Cerâmica Vermelha. Cerâmica Industrial, v. 2, n. 1/2, p. 31-35, jan./abr. 1997. ROSSIGNOLO, J. A. Concreto Leve Estrutural: produção, propriedades, microestrutura e aplicações. São Paulo: Pini, 2009.

SANTIS, B. C. Agregado Leve de Argila Calcinada Para Uso em Concreto Estrutural: viabilidade da cerâmica vermelha do estado de São Paulo. São Carlos, 2012. 132 f. Dissertação (Mestrado em Arquitetura) - Instituto de Arquitetura e Urbanismo de São Carlos, Universidade de São Paulo, São Carlos, 2012.

SANTOS, P. S. Ciência e Tecnologia das Argilas. 2. ed. ver. atual. São Paulo: Edgard Blücher, 1989a. v. 1.

SANTOS, P. S. Ciência e Tecnologia das Argilas. 2. ed. ver. atual. São Paulo. Edgard Blücher, 1989b. v. 2.

SERVIÇO BRASILEIRO DE APOIO ÀS MICRO E PEQUENAS EMPRESAS. Cerâmica Vermelha Para Construção: telhas, tijolos e tubos. São Paulo: Sebrae, 2008. Estudos de Mercado SEBRAE/ESPM.

TEZUKA, Y. Concreto Leve à Base de argila Expandida. São Paulo, 1973. Dissertação (Mestrado em Engenharia Civil) - Escola Politécnica da Universidade de São Paulo, São Paulo, 1973.

ZHANG, M. N.; GJ $\phi R V$, O. E. Mechanical Properties of High-Strength Lightweight Concrete.ACI Materials Journal,v. 88, n. 3, p. 240-247, 1991.

\section{Agradecimentos}

À Capes, ao CNPq e à Finep, pelo apoio financeiro para o desenvolvimento deste trabalho, ao Laboratório de Mecânica dos Solos do Departamento de Geotecnia da EESC/USP, ao Laboratório de Construção Civil do IAU/USP, ao Instituto de Geociências da USP, ao Laboratório de Construções Rurais e Ambiência da FZEA/USP e às empresas Cerâmica Josemar Ltda., Morandin Produto Cerâmicos, Selecta Blocos (Grupo Estrutural), Maristela Telhas Ltda. (Top Telha) e Cerâmica Vale do Mogi, por fornecerem matériaprima para a pesquisa. 


\section{Bruno Carlos de Santis}

Programa de Pós-Graduação em Engenharia e Ciência dos Materiais | Universidade de São Paulo | Av. Duque de Caxias Norte, 225, Centro | Pirassununga - SP - Brasil | CEP 13635-900 | Tel.: (19) 3565-6851 | E-mail: desantis.bruno@gmail.com

\section{João Adriano Rossignolo}

Faculdade de Zootecnia e Engenharia de Alimentos | Universidade de São Paulo | Tel.: (19) 3565-4284 | E-mail: j.a.rossignolo@gmail.com

\section{Revista Ambiente Construído}

Associação Nacional de Tecnologia do Ambiente Construído

Av. Osvaldo Aranha, $99-3^{\circ}$ andar, Centro

Porto Alegre - RS - Brasil

CEP $90035-190$

Telefone: +55 (51) 3308-4084

Fax: +55 (51) 3308-4054

www.seer.ufrgs.br/ambienteconstruido

E-mail: ambienteconstruido@ufrgs.br

32 Santis, B. C. de; Rossignolo, J. A. 